\title{
Apa Peran Jarak Kekuasaan Dalam Hubungan Antara Kepemimpinan Dan Perilaku Ekstra Warga Organisasi ?
}

\author{
Oleh: \\ Didik Subiyanto $^{1}$, Susanto ${ }^{2}$ \\ Fakultas Ekonomi Universitas Sarjanawiyata Tamansiswa, Yogyakarta \\ didiks@ustjogja.ac.id
}

\begin{abstract}
ABSTRAK
Peran ekstra karyawan akan membawa dampak yang sangat signifikan terhadap baik buruknya organisasi. Jika peran ektra karyawan tinggi maka akan menjadi keutungan bagi organisasi, dan demikian sebaliknya. Tujuan dari penelitian ini adalah untuk mengetahui secara mendalam peran Transformational Leadership dan Transactional Leadership terhadap Organizations Citizenship Behavior (OCB), dengan melibatkan Power Distance sebagai moderasi. Sampel diambil sebanyak 65 orang karyawan dari industri perhotelan di Daerah Istimewa Yogyakarta yang dilakukan secara acak dengan menggunakan aplikasi FormsApp. Data yang terkumpul diolah dengan menggunakan program SPSS. Data yang diolah telah memenuhi persyaratan kualitas data. Hasil penelitian memberikan penjelasan bahwa Transformational Leadership berpengaruh positif signifikan terhadap Organizational Citizenship Behavior (OCB), sedangkan Transactional Leadership terkonfirmasi secara empiris berpengaruh positif pada tingkat signifikansi yang lemah terhadap Organizational Citizenship Behavior (OCB). Selanjutnya hasil analisis menunjukkan bahwa Power Distance sebagai variabel moderasi memperlemah pengaruh Transformational Leadreship dan Transactional Leadership terhadap Organizational Citizenship Behavior. Implikasi dari hasil penelitian ini memberikan gambaran yang jelas dimana jika terjadi praktek-praktek pengelolaan sumber daya manusia yang menciptakan semakin lebarnya jarak hubungan antara atasan dan bawahan akan berdampak buruk terhadap kinerja organisasin karena rendahnya peran ekstra karyawan. Oleh sebab itu hasil penelitian ini dapat memberikan informasi dan arahan strategis dalam manajemen sumber daya manusia dalam upayaupaya untuk meningkatkan peran ekstra karyawan.
\end{abstract}

Keywords: Transformational Leadership, Transactional Leadership

\begin{abstract}
The extra role of employees will have a very significant impact on the good or bad of the organization. If the extra role of employees is high, it will be an advantage for the organization, and vice versa. The purpose of this study was to examine in depth the role of Transformational Leadership and Transactional Leadership in Organizations Citizenship Behavior (OCB), by involving Power Distance as moderation.The sample was taken as many as 65 employees from the hotel industry in the Special Region of Yogyakarta who were randomly assigned using the FormsApp.. The collected data were processed using the SPSS program. The processed data has met the data quality requirements.The results of the study provide an explanation that Transformational Leadership has a significant positive effect on Organizational Citizenship Behavior (OCB), while Transactional Leadership has been empirically confirmed to have a positive effect on a weak level of significance on Organizational Citizenship Behavior (OCB). Furthermore, the analysis results show that Power Distance as a moderating variable weakens the influence of Transformational Leadership and Transactional Leadership on Organizational Citizenship Behavior.The implication of the results of this study provides a clear picture where if there are human resource management practices that create a wider distance between superiors and subordinates, it will have a negative impact on organizational performance because of the low extra roles that employees have. Therefore the results of this study can provide information and strategic direction in human resource management in an effort to increase the extra role of employees.
\end{abstract}

Keywords: Transformational Leadership, Transactional Leadership. 


\section{PENDAHULUAN}

Perilaku warga organisasi (Organizational Citizenship Behavior) sangat menarik untuk dikaji, karena dapat menjadi faktor yang sangat penting terutama pengaruhnya terhadap kinerja perusahaan (Popescu et al., 2015), dan juga pengaruhnya pada kesuksesan perubahan organisasi (López-Domínguez et al., 2013). Perilaku warga organisasi (OCB) adalah konstruksi multidimensi, yang mencakup berbagai aspek perilaku diskresi yang tidak terkait langsung dengan perilaku konten pekerjaan.

Mengingat pentingnya peran OCB, sehingga menjadi sesuatu yang sangat memprihatinkan ketika suatu organisasi mengabaikan perannya. Pengabaian peran OCB oleh organisasi karena belum disadari adanya peran karyawan di luar tanggungjawab tugasnya. Oleh karena itu sudah seharusnya organisasi memberikan perhatian khusus terhadap OCB. Kajian tentang OCB telah banyak dilakukan seperti (Lin, 2014) dengan melibatkan prediktor Transformational Leadership, kemudian (Kao, 2017) dengan outcome kinerja organisasi.

Berkaitan denga bukti empiris peran kepemimpinan terhadap peran ekstra karyawan, studi tentang kepemimpinan terus menjadi upaya penelitian populer, terutama domain Transformational Leadership (TL). Pemimpin seringkali merupakan orang yang paling menonjol dalam lingkungan kerja dan cenderung memberikan pengaruh langsung pada perilaku bawahan,

Kepentingan organisasi dan anggotanya perlu diselaraskan, itulah tugas pemimpin transformasional (Bass, 1999). Selain itu (Bass, 1999) memberikan pernyataan terkait dengan peran pemimpin transaksional yang mempraktikkan penguatan pengikut kontingen, pemimpin transformasional menginspirasi, merangsang secara intelektual, dan secara individual mempertimbangkan mereka.

Sayangnya, beberapa penelitian terdaulu masih terlalu focus pada peran Transformational Leadership dalam memprediksi OCB, bagaimana peran Transactional Leadership dalam memprediksi OCB? dan apakah ada peran variabel lain, misal tentang budaya yang pernah diteliti oleh Hofstede, khususnya pada konteks di Negara yang sedang berkembang seperti di Indonesia.

Kembali pada peran kepemimpinan terhadap OCB, khususnya peran Transformational dan Transactional Leadership dalam memprediksi OCB, (Nahum-Shani \& Somech, 2011; Tjahjono et al., 2018) menemukan hubungan antara kepemimpinan transformasional dan OCB menjadi positif sejauh alokasientrisme meningkat, dan negatif sejauh idiosentrisme meningkat. Selain itu juga menemukan hubungan antara kepemimpinan transaksional dan OCB menjadi positif sejauh idiosentrisme meningkat dan negatif sejauh alokasientrisme meningkat.

Mekanisme perilaku pemimpin mempengaruhi OCB dengan peran moderasi Jarak Kekuasaan (Power Distance), belum diperhitungkan dalam penelitianpenelitian sebelumnya dalam konteks di Negara berkembang. Bedasarkan uraian dalam pendahuluan penelitian ini, peneliti tertarik dengan penelitian dengan tema peran Kepemimpinan Trasnformasionan dan Transaksional dalam memprediksi OCB dalam mekanisme budaya di Indonesia, khususnya Jarak Kekuasaan (Power Distance). Yang menarik dari penelitian ini adalah untuk menyelidiki efek moderasi Jarak Kekuasaan (Power Distance), pengaruh Transformational Leadership dan Transksional terhadap OCB pada konteks di Negara berkembang.

\section{KAJIAN PUSTAKA}

\section{Kepemimpinan}

Karekteristik seorang pemimpin haruslah menyiapkan bawahannya, sehingga bawahannya mampu menjelaskan ide dan keputusannya, dan bawahan merasa tertantang untuk menumbuhkan kekuatan kreativitasnya (Müceldili et al., 2013). Kepemimpinan terjadi ketika organisasi membangun kader-kader pemimpin masa depan yang memiliki kapasitas untuk membentuk budaya organisasi dan menciptakan pola keberhasilan (Ulrich \& Smallwood, 2012).

Yahaya \& Ebrahim, (2016) mengutip teori asli Bass mencakup tiga jenis perilaku transformasional (pengaruh ideal, stimulasi intelektual, dan pertimbangan individual) dan dua jenis perilaku transaksional (hadiah kontingen dan manajemen pasif dengan pengecualian).

Versi terbaru MLQ, MLQ (5X Short) dipergunakan oleh (Humphrey, 2012), untuk menilai variable Transformational Leadership dan perngaruhnya terhadap OCB. Pertamakali MLQ diformulasikan oleh Bass dan Avolio untuk menilai gaya kepemimpinan transformasional, transaksional, dan laissez-faire. MLQ berisi lima komponen perilaku untuk kepemimpinan transformasional: perilaku pengaruh ideal, atribusi pengaruh ideal, motivasi inspirasional, stimulasi intelektual, dan pertimbangan individual. Kepemimpinan transaksional terdiri dari tiga komponen perilaku: imbalan kontingen; manajemen aktif dengan pengecualian; dan manajemen pasif dengan pengecualian. Laissez-faire adalah faktor non-kepemimpinan. MLQ digunakan 
untuk menilai tiga faktor hasil: usaha ekstra; efektivitas pemimpin; dan kepuasan karyawan terhadap pemimpin.

Hasil beberapa penelitian terdahulu memberikan arahan yang jelas berkaitan dengan peran Transformational Leadership (Ardi et al., 2020; Subiyanto \& Djastuti, 2018; Kim \& Park, 2019). Arahan dan gambaran yang jelas mengenai masa depan organisasi, menginspirasi bagi seluruh karyawan untuk melihat masa depan organisasi, memberikan contoh kinerja yang mendukung perubahan organisasi serta mendorong bawahan untuk meningkatkan kompetensinya, tak lain adalah perilaku dari gaya Transformational Leadership.

Melengkapi peran gaya kepemimpinan transformasional, Transactional Leadership merupakan bagian dari gaya kepemimpinan di mana pemimpin mengembangkan kepatuhan pengikut melalui hadiah ataupun hukuman. Melalui sistem penghargaan dan hukuman, pemimpin transaksional dapat membuat para pengikut tetap termotivasi untuk jangka pendek. Meskipun Transactional Leadership dianggap sebagai prasyarat yang diperlukan agar Transformational Leadership menjadi efektif, namun masih kurang perhatian dari para peneliti maupun bagi para praktisi dalam memberikan perannya dalam keberhasilan organisasi (Aga, 2016). Dianggap sebagai salah satu yang paling luas tentang teori kepemimpinan, gaya transformasional dan transaksional memberikan arah perilaku yang saling melengkapi.

\section{Perilaku Ekstra Warga Organisasi (Organizational Citizenship Behavior)}

Organizational Citizenship Behavior (OCB) sebagai perilaku individu yang bersifat diskresioner, yang tidak secara langsung atau eksplisit terkait dengan sistem imbalan, dan bahwa secara agregat berfungsi meningkatkan efektifitas dari organisasi (Organ, 2015). OCB dapat menguntungkan organisasi dalam berbagai cara.

Dari sudut pandang sumber daya manusia, pertumbuhan daya saing organisasi tidak hanya terkait dengan tingkat pengetahuan karyawan dan perilaku formal terkait tugas pekerjaan, tetapi juga tentang perilaku informal karyawan. Beberapa dimensi yang membentuk perilaku diskresioner meliputi; Conscientiousness : Perilaku discretionary dari karyawan yang melampaui persyaratan peran minimum yang diputuskan oleh organisasi dalam bidang kehadiran, mematuhi peraturan, mengambil cuti, dan sebagainya; Sportsmanship: Kesediaan karyawan untuk menoleransi keadaan yang kurang ideal tanpa mengeluh; Courtes: Perilaku diskresioner dari pihak individu yang bertujuan mencegah masalah terkait pekerjaan dengan orang lain terjadi; Civil behavior: Perilaku individu yang menunjukkan bahwa dia bertanggung jawab, berpartisipasi dan terlibat serta peduli dengan kehidupan perusahaan; dan Altruism: membantu anggota organisasi lain terkait dengan masalah dan tugas, seperti karyawan yang membantu para pendatang baru atau orangorang berketerampilan rendah (Smith et al., 1983).

\section{Jarak Kekuasaan (Power Distance)}

Manajemen menyelesaikan sesuatu melalui orang (orang lain). Memahami orang berarti memahami latar belakang mereka, dan juga memprediksi perilaku dimasa depan. Latar belakang mereka telah memberi budaya tertentu, seperti hubungan sosial antara atasan dan bawahan.

Jarak kekuasaan (power distance) adalah sejauh mana para anggota yang kurang berkuasa dalam organisasi menerima bahwa kekuasaan didistribusikan secara tidak merata (Hofstede, 1994). Hal ini mencerminkan dari anggota yang kurang berkuasa dalam masyarakat/organisasi maupun mereka yang mempunyai kekuasaan lebih. Power Distance salah satu budaya yang paling sering dipelajari karena merupakan hal mendasar bagi semua ikatan dalam organisasi. Penerimaan ketidaksetaraan membentuk berbagai pandangan karyawan pada interaksi dalam organisasi (Hober et al., 2019). Cheung \& Pires, (2015) menyimpulkan bahwa jarak kekuasaan memiliki efek moderasi pada persepsi manajerial tentang dampak kepercayaan, salah satu dari enam dimensi kinerja bisnis.

\section{Hipotesis}

\section{Transformational Leadership, Transactional Leadership dan Organizational Citizenship Behavior}

Mengingat peran yang sangat efektif bagi organisasi, perilaku warga organisasi perlu ditempatkan pada posisi yang tinggi dalam manajemen sumber daya manusia stratejik. Menggerakan perilaku ekstra di luar tanggungjawab kerja karyawan diperlukan kepemimipinan yang mampu membangun persepsi dan sikap positif karyawan yang kemudian ditransformasikan oleh karyawan dalam tindakan ekstra di luar tugas pokoknya, namun efektif bagi prestasi organisasi. Peran Transformational Leadership dalam meningkatkan perilaku warga organisasi (Organizational Citizenship Behavior) dibuktikan secara empiris oleh (Lin, 2014; Kim \& Park, 2019). Sedangkan Transactional Leadership dapat mendorong efektivitas peran Transformational 
Leadership dalam meningkatkan peran ekstra karyawan (Asgari et al., 2019) . Dari uraian diatas dan berdasarkan hasil temuan penelitian empiris terdahulu, maka diajukan hipotesis sebagai berikut:

H1 Transformational Leadership berpengaruh secara signifikan positif terhadap Organizational Citizenship Behavior.

H2 Transactional Leadership berpengaruh signifikan positif terhadap Organizational Citizenship Behavior.

Peran moderasi Jarak Kekuasaan (Power Distance) pada Hubungan antara Transformational Leadership dan Transactional Leadership terhadap Organizational Citizenship Behavior

Penelitian ini dilakukan di Indonesia yang merupakan Negara berkembang dengan mendasarkan perspektif pada pertimbangan struktur budaya khususnya jarak kekuasan. Belum banyaknya penelitian terkait dengan peran moderasi jarak kekuasaan (Power Distance) pada pengaruh Transformational Leadership dan Transactional Leadership dalam memprediksi perilaku peran ekstra karyawan, maka dalam penelitian ini mengajukan hipotesis sebagai berikut:

H3 Jarak Kekuasaan (Power Distance) memperlemah pengaruh Transformational Leadership terhadap Organizational Citizenship Behavior.

H4 Jarak Kekuasaan (Power Distance) memperlemah pengaruh Transactional Leadership terhadap Organizational Citizenship Behavior.

\section{MODEL PENELITIAN}

Dari hipotesis yang diajukan di atas dapat digambarkan dalam Model Penelitian Empiris (Empirical Reseact Model) sebagai berikut:

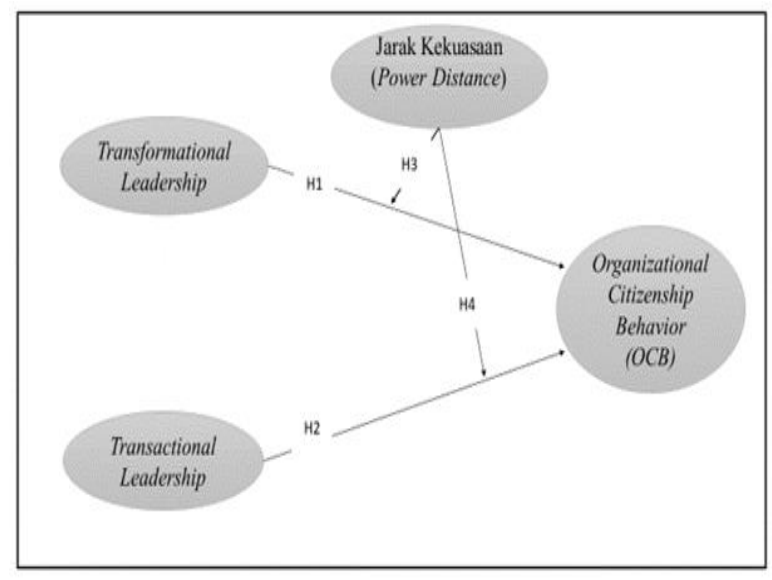

Gambar 1 Model Penelitian Empiris
Dari Model Penelitian Empiris (Empirical Reseacrh Model) di atas menjelaskan kausalitas dengan Transformational Leadership dan Transactional Leadership sebagai variable prediktor, Perilaku Warga Organisasi (Organizational Citizenship Behavior) sebagai variabel konsekuensi, dan Jarak Kekuasaan (Power Distance) sebagai variabel moderasi

\section{METODE PENELITIAN}

\section{Tinjauan Proses Penelitian}

Peneliti mengumpulkan data dengan menggunakan kuesioner yang didistribusikan secara online menggunakan FormsApp kepada karyawan perusahaan perhotelan. Penelitian ini mengukur empat variabel: Transformational Leadership, Transactional Leadership, Organizational Citizenship Behavior, dan Jarak Kekuasaan (Power Distance).

\section{Prosedur Pemilihan Sampel}

Kami mengambil sampel penelitian dari perusahaan perhotelan, dimana perusahaan perhotelan berkembang sangat pesat pada saat situasi normal, khususnya di kota wisata seperti di DIY. Dalam pengumpulan data awalnya menghubungi perusahaan bersangkutan dengan melakukan interaksi formal dan informal, selanjutnya mendistribusikan kuesioner dengan Form App. Data terkumpul sebanyak 65 responden.

\section{Pengukuran}

Item pertanyaan/pernyataan dinilai menggunakan skala lima poin mulai dari 1, "sangat tidak setuju", hingga 5, "Sangat setuju". Pengukuran variabel Transformational Leadership digunakan sebanyak lima item pernyataan. Transactional Leadership diukur dengan menggunakan empat item pernyataan, selanjutnya untuk variabel Perilaku Warga Organisasi (Organizational Citizenship Behavior) diukur dengan lima item pernyataan, dan variable moderasi Power Distance diukur menggunakan lima item pernyataan.

\section{Kualitas Data \\ Validitas dan Reliabilitas}

Sebelum data dianalisis terkait dengan hipotesis yang diajukan, data harus diuji terlebih dahulu validitas dan reliabilitasnya. Tabel 1 menjelaskan validitas dan reliabilitas masing-masing variabel. 
Tabel 1 Validitas dan Reliabilitas

\begin{tabular}{|c|c|c|c|c|c|c|}
\hline No & Variabel & Item & t hitung & t tabel & $\begin{array}{c}\text { Cronbach's } \\
\text { Alpha }\end{array}$ & Keterangan \\
\hline \multirow{5}{*}{1} & \multirow{5}{*}{$\begin{array}{l}\text { Transformation } \\
\text { al Leadership }\end{array}$} & $\mathrm{X} 1$ & 0.84 & \multirow{5}{*}{0.2058} & \multirow{5}{*}{0.895} & \multirow{5}{*}{$\begin{array}{r}\text { Valid dan } \\
\text { Reliabel }\end{array}$} \\
\hline & & $\mathrm{X} 2$ & 0.911 & & & \\
\hline & & X3 & 0.776 & & & \\
\hline & & $\mathrm{X} 4$ & 0.828 & & & \\
\hline & & $\mathrm{X} 5$ & 0.848 & & & \\
\hline \multirow{4}{*}{2} & \multirow{4}{*}{$\begin{array}{l}\text { Transactional } \\
\text { Leadership }\end{array}$} & X6 & 0.776 & \multirow{5}{*}{0.2058} & \multirow{4}{*}{0.847} & \multirow{4}{*}{$\begin{array}{r}\text { Valid dan } \\
\text { Reliabel }\end{array}$} \\
\hline & & $\mathrm{X} 7$ & 0.841 & & & \\
\hline & & $\mathrm{X} 8$ & 0.839 & & & \\
\hline & & $\mathrm{X} 9$ & 0.868 & & & \\
\hline \multirow{5}{*}{3} & \multirow{5}{*}{$\begin{array}{l}\text { Organizational } \\
\text { Citizenship } \\
\text { Behavior }\end{array}$} & Y1 & 0.778 & & \multirow{5}{*}{0.894} & \multirow{5}{*}{$\begin{array}{r}\text { Valid dan } \\
\text { Reliabel }\end{array}$} \\
\hline & & Y2 & 0.814 & \multirow{4}{*}{0.2058} & & \\
\hline & & Y3 & 0.858 & & & \\
\hline & & Y4 & 0.907 & & & \\
\hline & & Y5 & 0.831 & & & \\
\hline \multirow{5}{*}{4} & \multirow{5}{*}{ Power Distance } & PD1 & 0.778 & \multirow{5}{*}{0.2058} & \multirow{5}{*}{0.894} & \multirow{5}{*}{$\begin{array}{c}\text { Valid dan } \\
\text { Reliabel }\end{array}$} \\
\hline & & PD2 & 0.814 & & & \\
\hline & & PD3 & 0.858 & & & \\
\hline & & PD4 & 0.907 & & & \\
\hline & & PD5 & 0.831 & & & \\
\hline
\end{tabular}

Dari tabel 1 menunjukan semua indikator dari masing-masing variabel adalah valid dan reliabel.

\section{Statistik Deskriptif}

Tabel-tabel berikut menggambarkan kondisi demografi responden yang memberikan info tentang usia, jenis kelamin, dan tinggkat pendidikan.

Tabel 2 Descriptive Statistics berdasarkan usia

\begin{tabular}{ccc}
\hline $\begin{array}{c}\text { Jenjang } \\
\text { Usia }\end{array}$ & Frekuensi & Persen \\
\hline $20-24$ & 8 & 12.3 \\
$25-30$ & 25 & 38.5 \\
$31-35$ & 18 & 27.7 \\
36 keatas & 14 & 21.5 \\
\hline Total & 65 & 100.0 \\
\hline
\end{tabular}

Berdasarkan usia responden, usia antara 25 hingga 30 tahun merupakan karyawan terbanyak yaitu $38,5 \%$, dan rentang usia 20 hingga 24 tahun jumlah responden yang terendah. Selanjutnya pada tabel 3 menjelaskan demografi responden berdasarkan jenis kelamin:

\section{Tabel 3 Descriptive Statistics Berdasarkan Jenis} Kelamin

\begin{tabular}{ccc}
\hline Jenis Kelamin & Frequency & Percent \\
\hline Perempuan & 51 & 78.5 \\
Laki- Laki & 14 & 21.5 \\
\hline Total & 65 & 100.0 \\
\hline
\end{tabular}

Untuk kondisi demografi berdasarkan jenis kelamin didominasi oleh perempuan yaitu sebanyak 51 orang dari total responden 65 orang. Untuk tabel 4 berikut ini menjelaskan kondisi demografi berdasarkan tingkat pendidikan:

\section{Tabel 4 Descriptive Statistics Berdasarkan Tingkat Pendidikan}

\begin{tabular}{ccc}
\hline Pendidikan & Frequency & Percent \\
\hline S1 & 25 & 38.5 \\
D3 & 28 & 43.1 \\
SMA & 12 & 18.5 \\
\hline Total & 65 & 100.0 \\
\hline
\end{tabular}

Tingkat pendidikan responden $18,5 \%$ berpendidikan SMA atau sederajat, 43,1\% berpendidikan diploma (D3), dan sebanyak $38,5 \%$ berpendidikan sarjana (S1).

\section{Normalitas}

Sebelum data dianalisis untuk menjawab hipotesis yang diajukan dilakukan uji normalitas. Hasil uji normalitas data menunjukkan data normal dengan nilai Asymp. Sig. (2-tailed) sebesar 0,160 nilai ini menunjukkan data normal.

\section{Analisis Data}

Data dianalisis dengan dua tahap, yang pertama secara serentak tanpa melibatkan variabel moderasi, dan yang kedua regresi dengan melibatkan variabel moderasi.

\section{Hasil Analisis Regresi}

Dari proses analisis diperoleh nilai signifikansi dari pengaruh Transformational Leadership terhadap OCB sebesar 0.006 dengan estimasi positif sebesar 0,432 . Selanjutnya nilai signifikansi untuk pengaruh Transactional Leadership terhadap OCB sebesar 0,058 dengan estimasi sebesar 0,292 ini berarti terdapat signifikansi yang lemah dan positip pada level dibawah 0,1. Hasil temuan ini sejalan dengan penelitian yang telah dilakukan oleh (Nahum-Shani \& Somech, 2011).

Sedangkan secara serentak diperoleh nilai signifikansi sebesar 0.000 yang berarti secara bersama-sama variabel prediktor berpengaruh signifikan positif terhadap OCB. Sedangkan nilai Adjusted $R$ Square sebesar 0,454, pada hubungan secara bersama-sama Transformational Leadership, Transactioanal Leadership terhadap OCB. 
6 Coopetition, Vol XII, Nomor 1, Maret 2021, $1-8$

(E-ISSN : 2615-4978, P-ISSN : 2086-4620)

Tabel 5 Coefficients Prediktor terhadap Konsekuensi

\begin{tabular}{lccc}
\hline Model & \multicolumn{3}{c}{ Standardized Coefficients } \\
& Beta & $\mathrm{t}$ & $\mathrm{Sig}$ \\
\hline (Constant) & & 18 & .752 \\
$\begin{array}{l}\text { Transformational } \\
\text { Leadership }\end{array}$ & .432 & 362 & .006 \\
$\begin{array}{l}\text { Transactional } \\
\text { Leadership }\end{array}$ & .292 & 734 & .058 \\
\hline
\end{tabular}

a. Dependent Variable:OCB

\section{Uji Moderasi}

Setelah pengujian hipotesis tanpa melibatkan moderasi, langkah berikutnya adalah dengan menguji model dengan melibatkan variabel moderasi power distance. Pada tabel 6 berikut melibatkan variabel moderasi, dengan prediktor Transformational Leadership dan Transactional Leadership dengan konsekuensi Perilaku Warga Organisasi (Organizational Citizenship Behavior).

\section{Tabel 6 Coefficients dengan Moderasi Pertama}

\begin{tabular}{lccl}
\hline \multicolumn{1}{c}{ Model } & \multicolumn{3}{c}{ Standardized Coefficients } \\
& Beta & $\mathrm{t}$ & $\mathrm{Sig}$ \\
\hline (Constant) & & .197 & .845 \\
Transformational- & .288 & 1.002 & .320 \\
Leadership & .625 & 1.486 & .142 \\
Distance & .068 & .111 & .912 \\
POWER_1 &
\end{tabular}

a. Dependet Variable: OCB

Pada tabel 6 di atas nilai signifikansi peran moderasi dalam hubungan antara Transformational Leadership dan OCB sebesar 0,320 yang berarti variabel Power Distance memperlemah hubungan antara Transformational Leadership dan OCB, yang semula tanpa moderasi pada tingkat signifikansi 0,006. Selanjutnya tabel 7 memberikan informasi peran variable moderasi pada hubungan antara Transactional Leadership dan OCB.

Tabel 7 Coefficients dengan Moderasi Kedua

\begin{tabular}{lccc}
\hline \multicolumn{1}{c}{ Model } & \multicolumn{3}{c}{ Standardized Coefficients } \\
& Beta & $\mathrm{t}$ & Sig \\
\hline (Constant) & & .289 & .774 \\
Transformational- & .151 & .536 & .594 \\
Leadership & .576 & 1.509 & .136 \\
Distance & .190 & .332 & .741 \\
POWER_2 &
\end{tabular}

a. Dependent Variable: OCB

Pada tabel 7 di atas nilai signifikansi peran moderasi dalam hubungan antara Transactional Leadership dan
OCB sebesar 0,594 yang berarti variabel Power Distance memoderasi namun memperlemah pada hubungan antara Transactional Leadership dan OCB.

\section{HASIL DAN PEMBAHASAN}

Berdasarkan hasil analisis regresi dapat dijelaskan bahwa secara parsial menunjukkan bahwa Transformational Leadership berpengaruh signifikan positif terhadap OCB. Sedangkan pengaruh Transactional Leadership berpengaruh positip namun lemah terhadap OCB pada tinggkat signifikansi di bawah 0,1 . Dalam analisis regresi yang melibatkan variabel moderasi, menunjukkan bahwa variabel moderasi memperlemah pengaruh kedua variabel predictor tersebut, karena nilai signifikiansinya berada jauh diatas nilai sebelum melibatkan variable moderasi, yaitu Power Distance.

\section{SIMPULAN DAN SARAN}

\section{Simpulan}

Kesimpulan yang dapat diambil dari hasil analisis adalah bahwa secara parsial Transformational Leadership dapat meningkatkan derajat Perilaku Warga Organisasi (OCB) dan Transactional Leadership mampu meningkatkan Perilaku Warga Organisasi meskipun dalam signifikansi yang lemah. Selanjutnya peran moderasi Jarak Kekuasaan (Power Distance) memperlemah pengaruh Transformational Leadership dan Transactional Leadership terhadap Perilaku Warga Organisasi (Organizational Citizenship Behavior).

\section{Saran}

Implikasi: adalah jika praktek-praktek manajemen yang menimbulkan jarak kekuasaan antara atasan dan bawahan semakin lebar akan memperlemah peran ekstra karyawan, yang akan berdampak merugikan bagi perusahaan.

Saran untuk perusahaan perhotelan: gaya kepemimpinan transformasional perlu ditingkatkan, karena sangat berpengaruh terhadap peran ekstra karyawan. Selain itu pengelola perhotelan sebaiknya melaksanakan kegiatan majerial yang tidak memperlebar jarak antara atasan dan bawahan, terutama dalam kaitannya faktor psikologis, karena dapat memperlemah pengaruh kepemimpinan transformasional terhadap peran ekstra karyawan.

Saran untuk penelitian yang akan datang: diharapakan memperkaya model penelitian empiris untuk mengisi kekurangan dari penelitian ini, misalnya dengan memperluas sampel dengan melibatkan sample di luar DIY, ataupun memperkaya model dengan melibatkan variabel-variabel lain 
sebagai mediasi agar lebih komprehensip sebagai acuan dalam pengelolaaan perhotelan dengan perspektif yang lebih luas.

\section{DAFTAR PUSTAKA}

Aga, D. A. (2016). Transactional Leadership and Project Success: The Moderating Role of Goal Clarity. Procedia Computer Science. https://doi.org/10.1016/j.procs.2016.09.190

Ardi, Djati, S. P., Bernarto, I., Sudibjo, N., Yulianeu, A., Nanda, H. A., \& Nanda, K. A. (2020). The relationship between digital transformational leadership styles and knowledge-based empowering interaction for increasing organisational innovativeness. International Journal of Innovation, Creativity and Change.

Asgari, A., Mezginejad, S., \& Taherpour, F. (2019). The role of leadership styles in organizational citizenship behavior through the mediation of perceived organizational support and job satisfaction. Innovar https://doi.org/10.15446/innovar.v30n75.83259

Bass, B. M. (1999). Two Decades of Research and Development in Transformational Leadership. European Journal of Work and Organizational Psychology, 8(1), https://doi.org/10.1080/135943299398410

Cheung, R. S. Y., \& Pires, G. D. (2015). The role of power distance in the application of relationship marketing orientation to the internal business environment. Global Business and Economics Review. https://doi.org/10.1504/GBER.2015.070309

Hober, B., Schaarschmidt, M., \& von Korflesch, H. (2019). Internal idea contests: Work environment perceptions and the moderating role of power distance. Journal of Innovation and Knowledge. https://doi.org/10.1016/j.jik.2019.11.003

Hofstede, G. (1994). The business of international business is culture. International Business Review. $\quad$ https://doi.org/10.1016/09695931(94)90011-6

Humphrey, A. (2012). Transformational Leadership and Organizational Citizenship Behaviors: The Role of Organizational Identification. Psychologist-Manager Journal. https://doi.org/10.1080/10887156.2012.731831
Kao, R.-H. (2017). The relationship between work characteristics and change-oriented organizational citizenship behavior. Personnel Review. https://doi.org/10.1108/pr-01-2016-0012

Kim, E. J., \& Park, S. (2019). The role of transformational leadership in citizenship behavior: Organizational learning and interpersonal trust as mediators. International Journal of Manpower. https://doi.org/10.1108/IJM-12-2018-0413

Lin, R. S.-J. (2014). The Relationships between Transformational Leadership, Knowledge Sharing, Trust and Organizational Citizenship Behavior. International Journal of Innovation, Management and Technology. https://doi.org/10.7763/ijimt.2014.v5.508

López-Domínguez, M., Enache, M., Sallan, J. M., \& Simo, P. (2013). Transformational leadership as an antecedent of change-oriented organizational citizenship behavior. Journal of Business Research. https://doi.org/10.1016/j.jbusres.2013.02.041

Müceldili, B., Turan, H., \& Erdil, O. (2013). The Influence of Authentic Leadership on Creativity and Innovativeness. Procedia - Social and Behavioral Sciences, 99(June), 673-681. https://doi.org/10.1016/j.sbspro.2013.10.538

Nahum-Shani, I., \& Somech, A. (2011). Leadership, $\mathrm{OCB}$ and individual differences: Idiocentrism and allocentrism as moderators of the relationship between transformational and Transactional Leadership and OCB. Leadership Quarterly.

https://doi.org/10.1016/j.leaqua.2011.02.010

Organ, D. W. (2015). Organizational Citizenship Behavior. In International Encyclopedia of the Social \& Behavioral Sciences: Second Edition. https://doi.org/10.1016/B978-0-08-0970868.22031-X

Popescu, A. M., Deaconu, A., \& Popescu, T. (2015). Organization's Age and Organizational Citizenship Behavior (OCB), Performance Criteria at SMEs Level. Case Study - Bucharest - Ilfov Development Region. Procedia Economics and Finance. https://doi.org/10.1016/s2212-5671(15)00278-6

Smith, C. A., Organ, D. W., \& Near, J. P. (1983). Organizational citizenship behavior: Its nature and antecedents. Journal of Applied Psychology. https://doi.org/10.1037/0021-9010.68.4.653 
8 Coopetition, Vol XII, Nomor 1, Maret 2021, $1-8$

(E-ISSN : 2615-4978, P-ISSN : 2086-4620)

Subiyanto, D., \& Djastuti, I. (2018). Transformational leadership, organizational support, and dynamic ambidexterity capabilities in troubleshooting: Strategic efforts to improve lecturer performance empirical evidence from private universities in Central Java province and the Yogyakarta special region, Indonesia. Quality - Access to Success, 19(162), 96-101.

Tjahjono, H. K., Prasetyo, F., \& Palupi, M. (2018). KEPEMIMPINAN TRANSFORMASIONAL PADA ORGANIZATIONAL CITIZENSHIP BEHAVIOR DAN KOMITMEN AFEKTIF. Jurnal Manajemen Dan Pemasaran Jasa. https://doi.org/10.25105/jmpj.v11i2.2771

Ulrich, D., \& Smallwood, N. (2012). Advances in Global Leadership Article information: In Advances in Global Leadership.

Yahaya, R., \& Ebrahim, F. (2016). Leadership styles and organizational commitment: literature review. Journal of Management Development, 35(2), 190-216. https://doi.org/10.1108/JMD-012015-0004 